\title{
Severe conjunctivitis associated with chlamydia felis infection in a free-ranging Eurasian Lynx (Lynx lynx)
}

\begin{abstract}
Marti, Iris ; Pisano, Simone R R ; Wehrle, Martin ; Meli, Marina L ; Hofmann-Lehmann, Regina ;
\end{abstract} Ryser-Degiorgis, Marie-Pierre

\begin{abstract}
A free-ranging adult Eurasian lynx (Lynx lynx) captured in Switzerland presented with a severe purulent unilateral conjunctivitis. Chlamydia felis was detected in conjunctival swabs by $\mathrm{qPCR}$. Systemic treatment with oxytetracycline and ketoprofen led to complete recovery. Infection with C. felis has not been previously reported in Eurasian lynx.
\end{abstract}

DOI: https://doi.org/10.7589/2018-05-142

Posted at the Zurich Open Repository and Archive, University of Zurich

ZORA URL: https://doi.org/10.5167/uzh-158198

Journal Article

Published Version

Originally published at:

Marti, Iris; Pisano, Simone R R; Wehrle, Martin; Meli, Marina L; Hofmann-Lehmann, Regina; RyserDegiorgis, Marie-Pierre (2019). Severe conjunctivitis associated with chlamydia felis infection in a freeranging Eurasian Lynx (Lynx lynx). Journal of Wildlife Diseases, 55(2):522.

DOI: https://doi.org/10.7589/2018-05-142 


\title{
Severe Conjunctivitis Associated with Chlamydia felis Infection in a Free-ranging Eurasian Lynx (Lynx lynx)
}

\begin{abstract}
Iris Marti, ${ }^{1,4}$ Simone R. R. Pisano, ${ }^{1}$ Martin Wehrle, ${ }^{2}$ Marina L. Meli, ${ }^{3}$ Regina Hofmann-Lehmann, ${ }^{3}$ and MariePierre Ryser-Degiorgis ${ }^{1}{ }^{1}$ Centre for Fish and Wildlife Health, Vetsuisse Faculty, University of Bern, Länggassstr. 122, CH-3001 Bern, Switzerland; ${ }^{2}$ Natur- und Tierpark Goldau, Parkstr. 26, Postfach 161, 6410 Goldau, Switzerland; ${ }^{3}$ Clinical Laboratory and Center for Clinical Studies, Vetsuisse Faculty, University of Zurich, Winterthurerstr. 260, CH8057 Zürich, Switzerland; ${ }^{4}$ Corresponding author (email: iris.marti@ vetsuisse.unibe.ch)
\end{abstract}

ABSTRACT: A free-ranging adult Eurasian lynx (Lynx lynx) captured in Switzerland presented with a severe purulent unilateral conjunctivitis. Chlamydia felis was detected in conjunctival swabs by qPCR. Systemic treatment with oxytetracycline and ketoprofen led to complete recovery. Infection with C. felis has not been previously reported in Eurasian lynx.

Chlamydia felis is an obligate intracellular bacterium and is the organism most-frequently associated with infectious conjunctivitis in domestic cats (Felis silvestris catus; Dean et al. 2005; Gruffydd-Jones et al. 2009). After 2$5 \mathrm{~d}$ incubation, clinical signs typically include a marked hyperemia of the nictitating membrane, prominent chemosis, blepharospasm, and ocular discharge (Gruffydd-Jones et al. 2009; Berris et al. 2015). They often start unilaterally but become bilateral after a few days. Chlamydiosis in cats can additionally be associated with fever, infection of the upper respiratory tract, pneumonia, and reproductive disorders (Gruffydd-Jones et al. 2009).

In wild felids, antibodies against Chlamydia spp. have been documented in free-ranging Iberian lynx (Lynx pardinus), European wildcats (Felis silvestris silvestris), and captive tigers (Panthera tigris; Millán and Rodríguez 2009; Millán et al. 2009; Berris et al. 2015) but not in mountain lions (Puma concolor) and Pallas cats (Felis manul; Paul-Murphy et al. 1994; Naidenko et al. 2014). Chlamydia felis was detected by PCR in a free-ranging Iberian lynx and a captive ocelot (Leopardus pardalis; Meli et al. 2009; Seki et al. 2016) without mention of any associated clinical signs. The avian immunotype of C. psittaci was found in the altered organs of a captive fishing cat (Prionailurus viverrinus) that died after showing depression and tremor (Kik et al. 1997).
Here we report a case of conjunctivitis associated with $C$. felis infection in a freeranging Eurasian lynx (Lynx lynx).

In March 2017, an adult female Eurasian lynx was caught for a translocation program in the Jura Mountains, Switzerland, using a box trap and an intramuscular injection of 0.17 $\mathrm{mg} / \mathrm{kg}$ medetomidine (Domitor, $1 \mathrm{mg} / \mathrm{mL}$, Orion-Corporation, Espoo, Finland) and 4.9 $\mathrm{mg} / \mathrm{kg}$ ketamine hydrochloride (Ketasol, 100 $\mathrm{mg} / \mathrm{mL}$, Graeub AG, Bern, Switzerland). The animal presented with a marked unilateral conjunctivitis of the left eye characterized by hyperemia, prominent chemosis, and yellowish, turbid, mucopurulent discharge (Fig. 1). There was no visible injury of the ocular structures, and the fluorescein stain test was negative, but two, crust-covered scratches on the nose suggested a recent facial trauma. The right eye appeared healthy. The lynx was in good body condition $(16.2 \mathrm{~kg})$ and had a shiny clean hair coat and a full stomach. Body temperature (38.7 C), lung, and heart auscultation were unremarkable. We suspected a bacterial conjunctivitis of traumatic origin. According to our translocation protocol, we collected blood as well as conjunctival, oropharyngeal, and rectal dry swabs. We rinsed the diseased eye with sterile $\mathrm{NaCl}$ solution and administered $8 \mathrm{mg} / \mathrm{kg}$ cefovecin (Convenia ${ }^{\circledR}, 80 \mathrm{mg} / \mathrm{mL}$, Zoetis, Zurich, Switzerland) subcutaneously. Medetomidine was antagonized with $0.86 \mathrm{mg} / \mathrm{kg}$ atipamezol (Antisedan, $5 \mathrm{mg} / \mathrm{mL}$, Orion-Corporation, Espoo, Finland) and the lynx was brought to a quarantine enclosure.

Conjunctival swabs were positive for $C$. felis by qPCR (cycle threshold [Ct] values of 27 in the affected versus 39 in the apparently healthy eye, or almost 4,000 times more 


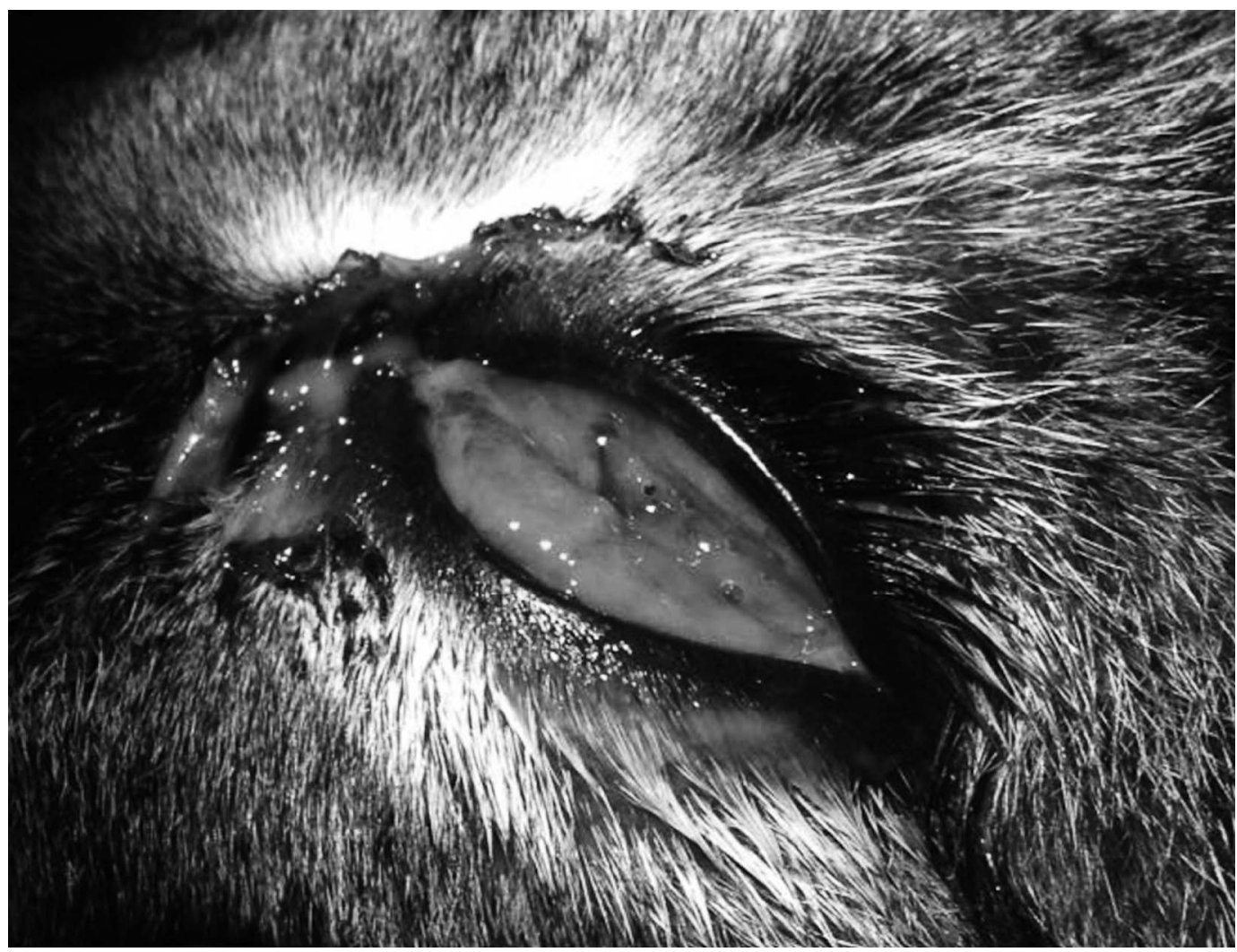

Figure 1. Left eye of an adult female Eurasian lynx (Lynx lynx) at the time of capture in March 2017 in the Swiss Jura Mountains. The lynx presented with a severe conjunctivitis characterized by hyperemia and prominent chemosis together with yellowish, turbid, mucopurulent ocular discharge.

bacterial DNA in the affected eye than in the unaffected eye) while PCRs for feline herpesvirus-1 (FHV-1) and Mycoplasma felis were negative (Meli et al. 2009; Söderlund et al. 2011). The PCRs for feline calicivirus (FCV), canine distemper virus (oropharyngeal swab), parvovirus, feline coronavirus (rectal swab), and feline leukemia provirus (FeLV; blood) were negative (Meli et al. 2009). Western blot for feline immunodeficiency virus antibodies and enzyme-linked immunosorbent assay (ELISA) for FeLV p27 antigen were negative (Lutz et al. 1988). Hematology and blood chemistry did not reveal abnormalities compared to apparently healthy, free-ranging lynx from Switzerland.

The available data pointed at a chlamydial conjunctivitis. An intramuscular injection of $9.7 \mathrm{mg} / \mathrm{kg}$ oxytetracycline (Engemycin ${ }^{\circledR}, 100$
mg/mL, MSD Animal Health, Luzern, Switzerland) mixed with $1.8 \mathrm{mg} / \mathrm{kg}$ ketoprofen (Dinalgen ${ }^{\circledR}, 150$ mg/mL, Graeub AG, Bern, Switzerland) was administered by blowpipe every second day over a period of $8 \mathrm{~d}$. Initial signs of severe blepharospasm, anorexia, and apathy progressively resolved and by the end of the treatment, the lynx appeared healthy. It was re-examined and resampled under anesthesia $14 \mathrm{~d}$ postcapture. Both eyes were clinically inconspicuous and body condition was good $(16.5 \mathrm{~kg})$. No tissue irritations related to the oxytetracycline injections were observed. Conjunctival swabs were PCRnegative for C. felis. The lynx was fitted with a global positioning system (GPS) radiocollar and released into the wild. It was photographed with a camera-trap 3 mo later and 
appeared in good body condition, with a normal left eye.

Here we have reported a novel case of a $C$. felis infection with associated conjunctivitis in a free-ranging wild felid. A higher load of $C$. felis DNA was detected in the affected left than in the healthy right eye, suggesting a recent bacterial spread from left to right. The observed ocular signs, the rapid clinical improvement under appropriate treatment, and the absence of FHV-1, FCV, and M. felis supported the etiologic role of C. felis. In domestic cats with ocular chlamydiosis, spontaneous remissions occur (Gruffydd-Jones et al. 2009), but short treatment periods can result in chronic persistent infections and recurrence of clinical signs (Dean et al. 2005). In this lynx, the negative PCR results obtained $9 \mathrm{~d}$ after the first oxytetracycline injection and the inconspicuous picture 3 mo after release suggested a complete recovery.

The source of infection was unknown. Natural transmission occurs by close contact, with ocular secretions playing a key role (Gruffydd-Jones et al. 2009; Berris et al. 2015; Seki et al. 2016). Nevertheless, Chlamydiaceae can survive in the environment for a limited time, making indirect infection possible (Horzinek et al. 2005). Considering the apparently isolated occurrence in a lynx, a spill-over from a domestic cat (Felis catus) or European wildcat is a potential explanation. Both domestic cats and European wildcats share the range of lynx in the Jura Mountains (Hercé 2011). Direct contacts between lynx and cats occasionally occur by predation (Jobin et al. 2000). Shared-scent marking sites might provide opportunities for indirect contacts. As yet, no data on the exposure of Eurasian lynx to C. felis are available, and investigations on the occurrence of Chlamydia spp. in sympatric felids are necessary to draw conclusions about the infection dynamics. This case highlights the benefit of a quarantine period to treat and prevent the spread of infectious diseases when translocating wildlife.

We thank the collaborators of the KORA (Carnivore Ecology and Wildlife Management Switzerland), the Tierpark Goldau, and the
Nationalpark Kalkalpen for their contributions.

\section{LITERATURE CITED}

Berris F, Tolentino J, Flores M, Reyes MF. 2015. Detection of Chlamydophila felis antibodies in Felis catus and Panthera tigris at a wildlife facility using ELISA. Philipp J Vet Anim Sci 41:80-84.

Dean R, Harley R, Helps C, Caney S, Gruffydd-Jones T. 2005. Use of quantitative real-time PCR to monitor the response of Chlamydophila felis infection to doxycycline treatment. J Clin Microbiol 43:18581864.

Gruffydd-Jones T, Addie D, Belák S, Boucraut-Baralon C, Egberink H, Frymus T, Hartmann K, Hosie MJ, Lloret A, Lutz H. 2009. Chlamydophila felis infection. ABCD guidelines on prevention and management. J Feline Med Surg 11:605-609.

Hercé T. 2011. Spatio-temporal interactions between sympatric felids in the Swiss Jura Mountains. Internship report, Université de Franche-Comté, Besançon, France. http://www.kora.ch/fileadmin/ file_sharing/5_Bibliothek/52_KORA_Publikationen/ 524_Thesis/Herce_2011_Spatio-temporal_ interactions_between_sympatric_felids_Swiss_Jura_ Mountains.pdf. 21 pp. Accessed April 2018.

Horzinek MC, Schmidt V, Lutz H, editors. 2005. Krankheiten der Katze, 4. überarb. Aufl. Enke, Stuttgart, Germany, $880 \mathrm{pp}$

Jobin A, Molinari P, Breitenmoser U. 2000. Prey spectrum, prey preference and consumption rates of Eurasian lynx in the Swiss Jura Mountains. Acta Theriol 45:243-252.

Kik MJL, van der Hage MH, Greydanus-van der Putten SWM. 1997. Chlamydiosis in a fishing cat (Felis viverrina). J Zoo Wildl Med 28:212-214.

Lutz H, Arnold P, Hübscher U, Egberink H, Pedersen N, Horzinek MC. 1988. Specificity assessment of feline T-lymphotropic lentivirus serology. J Vet Med Ser B 35:773-778.

Meli ML, Cattori V, Martínez F, López G, Vargas A, Simón MA, Zorrilla I, Muñoz A, Palomares F, LópezBao JV, et al. 2009. Feline leukemia virus and other pathogens as important threats to the survival of the critically endangered Iberian lynx (Lynx pardinus). PLoS One 4:e4744.

Millán J, Candela MG, Palomares F, Cubero MJ, Rodríguez A, Barral M, de la Fuente J, Almería S, León-Vizcaíno L. 2009. Disease threats to the endangered Iberian lynx (Lynx pardinus). Vet J 182: 114-124.

Millán J, Rodríguez A. 2009. A serological survey of common feline pathogens in free-living European wildcats (Felis silvestris) in central Spain. Eur J Wildl Res 55:285-291.

Naidenko SV, Pavlova EV, Kirilyuk VE. 2014. Detection of seasonal weight loss and serologic survey of 
potential pathogens in wild Pallas' cats (Felis [otocolobus] Manul) of the Daurian Steppe, Russia. J Wildl Dis 50:188-194.

Paul-Murphy J, Work T, Hunter D, McFie E, Fjelline D. 1994. Serologic survey and serum biochemical reference ranges of the free-ranging mountain lion (Felis concolor) in California. J Wildl Dis 30:205-215.

Seki MC, André MR, Carrasco AOT, Machado RZ, Pinto AA. 2016. Detection of Chlamydophila felis and feline herpesvirus type-1 in non-domestic felids in Brazil. Braz J Vet Res Anim Sci 53:169-176.

Söderlund R, Bölske G, Holst BS, Aspán A. 2011.

Development and evaluation of a real-time polymerase chain reaction method for the detection of Mycoplasma felis. J Vet Diagn Invest 23:890-893.

Submitted for publication 30 May 2018.

Accepted 17 August 2018. 